\title{
Drivers of wing shape in a widespread Neotropical bird: a dual role of sex-specific and migration-related functions
}

\author{
Ivan C. Carvalho Provinciato ${ }^{1}$ - Márcio S. Araújo ${ }^{1}$ - Alex E. Jahn ${ }^{1,2}$ (D)
}

Received: 16 October 2017 / Accepted: 7 July 2018 / Published online: 11 July 2018

(c) Springer Nature Switzerland AG 2018

\begin{abstract}
A large body of research has shown how avian morphology is shaped by specific behavioral repertoires and life history traits. Yet, the majority of such research has been conducted on birds breeding at north-temperate latitudes. We tested the hypothesis that functional wing traits of Fork-tailed Flycatchers (Tyrannus savana), which migrate within South America, vary predictably between non-migratory and migratory flycatchers. Additionally, due to sex-specific differences in this species (e.g., males perform courtship displays), we explored sex-related variation in wing shape. We applied classic measures of wing shape (e.g., wing loading, length, aspect ratio, pointedness), as well as landmark-based morphometric analysis to describe the wing morphology of Fork-tailed Flycatchers from breeding populations across South America. We found that migratory flycatchers tend to have more pointed wings than non-migratory flycatchers. Additionally, we found that males have wings that are significantly longer, more pointed, with a higher aspect ratio and that are more swept than those of females, regardless of whether they migrate or not. Overall, our results suggest that wing shape of Fork-tailed Flycatchers is the result of a complex set of tradeoffs shaped by selective pressures exerted on both sexes (i.e., the need to forage on the wing, evade predators and migrate efficiently), as well as sex-specific behaviors (e.g., the need for males to execute acrobatic displays).
\end{abstract}

Keywords Argentina $\cdot$ Austral $\cdot$ Brazil $\cdot$ Flight $\cdot$ Landmark-based morphometrics

\section{Introduction}

For a bird, efficient flight requires a complex suite of specialized adaptations molded by selective pressures related to the need to forage (e.g., capturing arthropod prey on the wing vs. on the ground), evade predators, attract mates (e.g., flight displays), migrate, and occupy different habitat types (e.g., forest vs. grassland). Wing shape in particular has been

Alex E. Jahn

jahna@si.edu

1 Instituto de Biociências de Rio Claro, Universidade Estadual Paulista (UNESP), Av. 24A, No. 1515, Rio Claro, SP, Brazil

2 Present Address: Smithsonian Conservation Biology Institute, Migratory Bird Center, 3001 Connecticut Ave. NW, Washington, DC 20008, USA 
shown to be highly variable across species, populations, sexes and ages (reviewed by Balmford et al. 1994; Fernández and Lank 2007; de la Hera et al. 2014). For example, juveniles tend to have more rounded wings than adults (e.g., Pérez-Tris and Tellería 2001; de la Hera et al. 2014), and compared to sedentary birds, migrants tend to have more pointed, higher aspect ratio wings (Voelker 2001; Milá, et al. 2008; Baldwin et al. 2010; Outlaw 2011).

High aspect ratio, pointed wings are more aerodynamically efficient than rounded wings during migration (e.g., Pennycuick 1972; Rayner 1988; Winkler and Leisler 1992; Lockwood et al. 1998; Bowlin and Wikelski 2008), and both aspect ratio (Fiedler 2005; Vágási et al. 2016) and wing pointedness have been shown to be positively associated with migration distance (e.g., Marchetti et al. 1995; Mönkkönen 1995; Arizaga et al. 2006; Outlaw 2011; Minias et al. 2015). Wing length has also been shown to be positively associated with migration (e.g., Pérez-Tris and Tellería 2001, Förschler and Bairlein 2011) and with a bird's capacity to adjust migration timing (Hahn et al. 2016). Additionally, more swept wings allow for less drag during flapping flight (van Oorschot et al. 2016). Finally, given that flight speed is positively related to wing loading (Pennycuick 2008), higher wing loading and aspect ratio are advantageous when minimizing time on migration is important, whereas if reducing the energetic cost of transporting mass is under selection, birds should have lower wing loading (Yong and Moore 1994; Rayner 1988; Bowlin 2007).

Yet, we still lack a comprehensive understanding about the mechanistic underpinnings of wing shape across a taxonomically, behaviorally and ecologically broad spectrum of birds. As exemplified by prior work, the majority of research on functional morphology of the avian wing has focused on species that breed at north-temperate latitudes (primarily North America and Europe), which may not be representative of birds across the planet. For example, many migratory birds that breed at north-temperate latitudes must cross large barriers such as the Mediterranean Sea, Sahara Desert or the Gulf of Mexico (i.e., Nearctic-Neotropical and Palearctic-Paleotropical migrants; Newton 2010), which can exert significant selective pressures on wing shape (e.g., Corman et al. 2014; Buler et al. 2017). In contrast, migratory birds that breed at south-temperate and tropical latitudes often have few or no barriers to cross (e.g., those migrating in South America; Chesser 1994). Likewise, although a large body of work has focused on the evolution of sexually-selected traits in birds, there is still no consensus on the tradeoffs associated with sexual selection in migratory versus non-migratory birds (Collins et al. 2009; Byers 2011), or on which mechanisms drive trait patterns across latitudes (Kaluthota et al. 2016).

Sex-specific migratory strategies and roles during the breeding season could also lead to sexual variation in wing shape. For example, in various bird species, protandry (the early arrival to breeding grounds by males relative to females) is well documented (reviewed by Morbey and Ydenberg 2001). Such an early arrival could be in part a product of wings that are better adapted to faster migration (Hedenström and Pettersson 1986). In Swainson's Thrushes (Catharus ustulatus), those with more pointed wingtips and lower wing loading have an earlier spring migration schedule than those with rounder wings and higher wing loading (Bowlin 2007). In Fork-tailed Flycatchers (Tyrannus savana; Vieillot 1808), another major difference between the sexes is the longer tail of males versus females, which could exert selective pressure on wing shape. Tails are important for generating lift and maneuverability (Thomas and Balmford 1995), but long tails can generate drag that make straight, forward (e.g., migratory) flight more energetically expensive (Møller et al. 1995). Additionally, male but not female Fork-tailed Flycatchers perform acrobatic display flights consisting of a series of spiral flights and somersaults in mid-air (Mobley 2004; Jahn and Tuero 2013; AEJ, pers. observation). Although displays are typical of the genus Tyrannus (Smith 1966; Regosin and Pruett-Jones 1995; Mobley 2004), and the family (i.e., 
New World Tyrannid flycatchers; reviewed by Fitzpatrick 2004; Areta and Miller 2014), little is known about their function in this family. Hedenström and Møller (1992) found that, in passerine bird species with song flight (i.e., an aerial display exhibited by males), wings were longer, aspect ratio was higher and wing loading was lower in males than in females; nevertheless, they point out that substantial interspecific differences could exist.

We studied the Fork-tailed Flycatcher (hereafter, "flycatchers"), a widespread Neotropical bird, to test hypotheses about the effects of migration and sex on wing shape. The nominate subspecies (T. s. savana) breeds from central Brazil to Argentina and migrates to overwinter in northern South America, primarily within the Orinoco River Basin (Mobley 2004; Jahn et al. 2013), whereas the subspecies monachus breeds in northern South America and does not migrate (Hilty and Brown 1986; Fig. 1). Both male and female flycatchers depend heavily on their wings when foraging, which they do by gleaning fruit and arthropods from vegetation and by capturing flying arthropods (Mobley 2004). We predicted that migratory flycatchers should have longer, higher aspect ratio, more pointed and swept wings than non-migratory flycatchers. Because little is known about this flycatcher's migratory strategy (i.e., whether it is an energy maximizer or time minimizer on migration), we have no specific prediction regarding wing loading versus presence/absence of migration. We also evaluated whether flycatcher wing morphology is sexually dimorphic. Because little information exists on the selective pressures exerted on wing shape due to the display performed by males, nor on the migratory strategy of males versus females, we have no specific prediction about sexual differences in wing shape due to those behaviors.

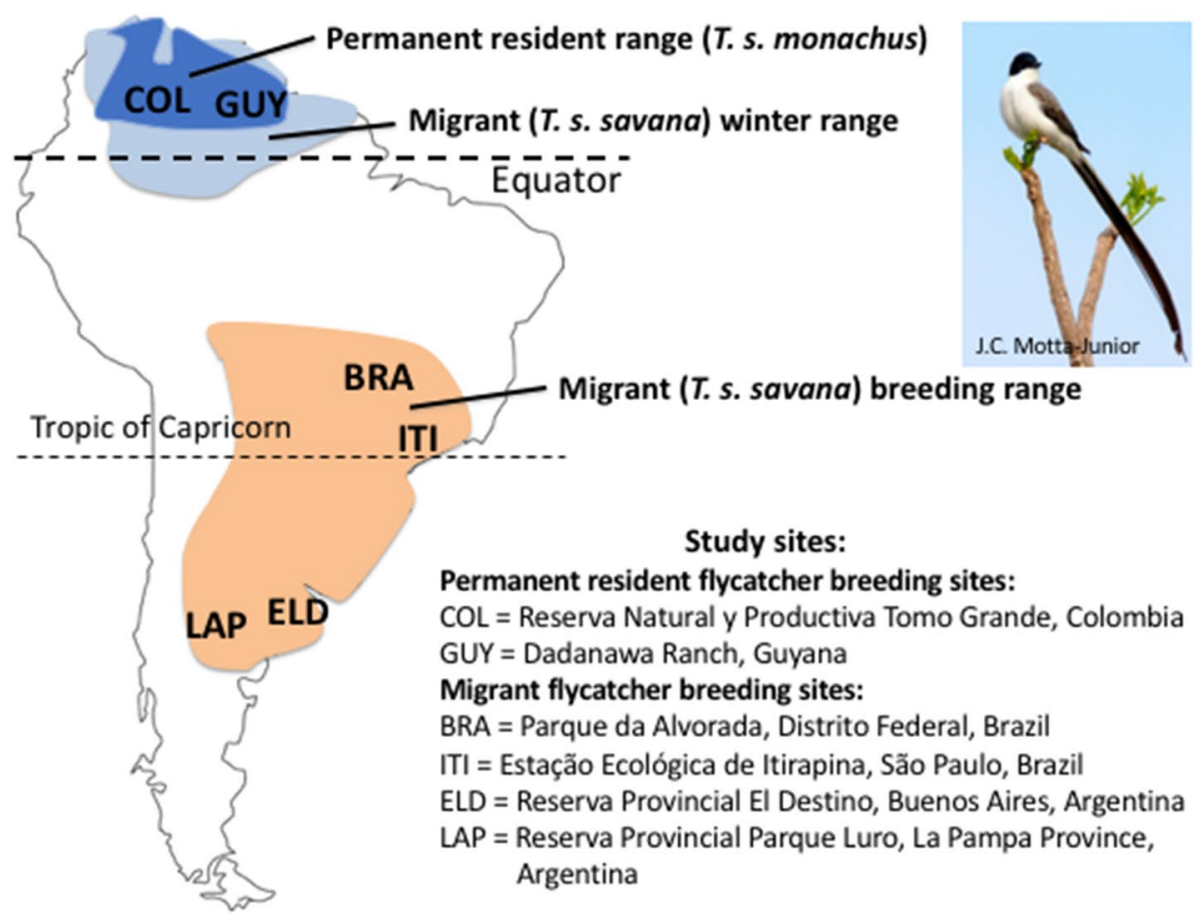

Fig. 1 Location of study sites and distribution of migrant and non-migratory/permanent resident Fork-tailed Flycatchers in South America 
Instead, due to the potential for longer tails to impact wing shape because of the drag they can generate, we explored whether a relationship exists between tail length and wing shape among males.

\section{Materials and methods}

We captured and measured migratory flycatchers during the breeding season (Sep to Jan; Marini et al. 2009; Jahn et al. 2017), at the following sites (Fig. 1): Parque da Alvorada, Distrito Federal, Brazil $\left(15.8^{\circ} \mathrm{S}, 47.8^{\circ} \mathrm{W}\right)$, which is a park located within the city limits of Brasilia, primarily composed of short grass with scattered trees; we captured flycatchers on 19 Oct 2013 and 23 Sep to 20 Oct 2014; Estação Ecológica de Itirapina, São Paulo State, Brazil $\left(22.3^{\circ} \mathrm{S}, 47.9^{\circ} \mathrm{W}\right)$, which is primarily composed of low campo and cerrado grassland; we captured flycatchers here from 12 to 21 Nov 2013, 1 Oct to 2 Dec 2014, and 7 Nov to 6 Dec 2015; Reserva Natural El Destino, Buenos Aires Province, Argentina $\left(35.1^{\circ} \mathrm{S}, 57.4^{\circ} \mathrm{W}\right)$, which is primarily composed of temperate grasslands and marshes grazed by cattle, intersected by woodland tracts dominated by Celtis ehrenbergiana and Scutia buxifolia; we captured flycatchers here from 18-29 Dec 2013 and 23-31 Dec 2014; Reserva Provincial Parque Luro, neighboring private properties, and along a nearby road right-of-way $\left(36.8^{\circ} \mathrm{S}, 64.3^{\circ} \mathrm{W}\right)$ in La Pampa Province, Argentina, composed primarily of tracts of Prosopis caldenia trees and grasslands with scattered bushes, with nearby agricultural fields; we captured flycatchers here from 22-31 Dec 2013, 14 Nov 2014 to 6 Jan 2015, and 11-31 Jan 2016.

We measured non-migratory flycatchers ( $T$. s. monachus) during the breeding season (Mar to Apr; Jahn et al. 2017) at the following sites (Fig. 1): Reserva Natural y Productiva Tomo Grande, Vichada Department, Colombia $\left(4.9^{\circ} \mathrm{N}, 70.2^{\circ} \mathrm{W}\right)$, primarily composed of grasslands (llanos) with low scattered trees (Curatella sp.), as well as gallery forest along the Tomo River; we captured flycatchers here from 19 to 26 Mar 2014; Dadanawa Ranch, Guyana $\left(2.8^{\circ} \mathrm{N}, 59.5^{\circ} \mathrm{W}\right)$, consisting of seasonally inundated grasslands bordered by humid gallery forest along streams, with low-intensity cattle grazing; we captured flycatchers here from 1 to 7 Apr 2015.

Data collection: Breeding flycatchers were captured near their nests using methods in Jahn et al. (2017) and banded with an individually numbered metal band and up to three Darvic color bands. Primary feathers of juvenile flycatchers lack notches, whereas adults (i.e., individuals that are at least 1 year old) have notches at the tips of their primary feathers (Pyle 1997; Jahn et al. 2016; Fig. 2). We therefore classified flycatchers with notched primaries as adults (i.e., those at least 1 year old). Flycatchers were sexed using the shape of the notch of primaries 8-10 or the presence of a brood patch or cloacal protuberance (Pyle 1997). We quantified flight feather molt by noting which primaries (10 feathers/wing in Tyrannid flycatchers; Pyle 1997) and secondaries (6 feathers/wing) were molting on each wing. We measured tarsus and bill length (from the front of the nare to the bill tip) using plastic dial calipers (to the nearest $0.1 \mathrm{~mm}$ ), and body mass (to the nearest $0.1 \mathrm{~g}$ ) using a portable digital scale (Ohaus LS 200). Finally, we measured wing pointedness as the distance between the tip of the longest primary feather and the tip of the first secondary feather on the closed wing, to the nearest millimeter (i.e., Kipp's Index; Bowlin and Wikelski 2008; Milá et al. 2008), although this was not done on all flycatchers due to time constraints. 


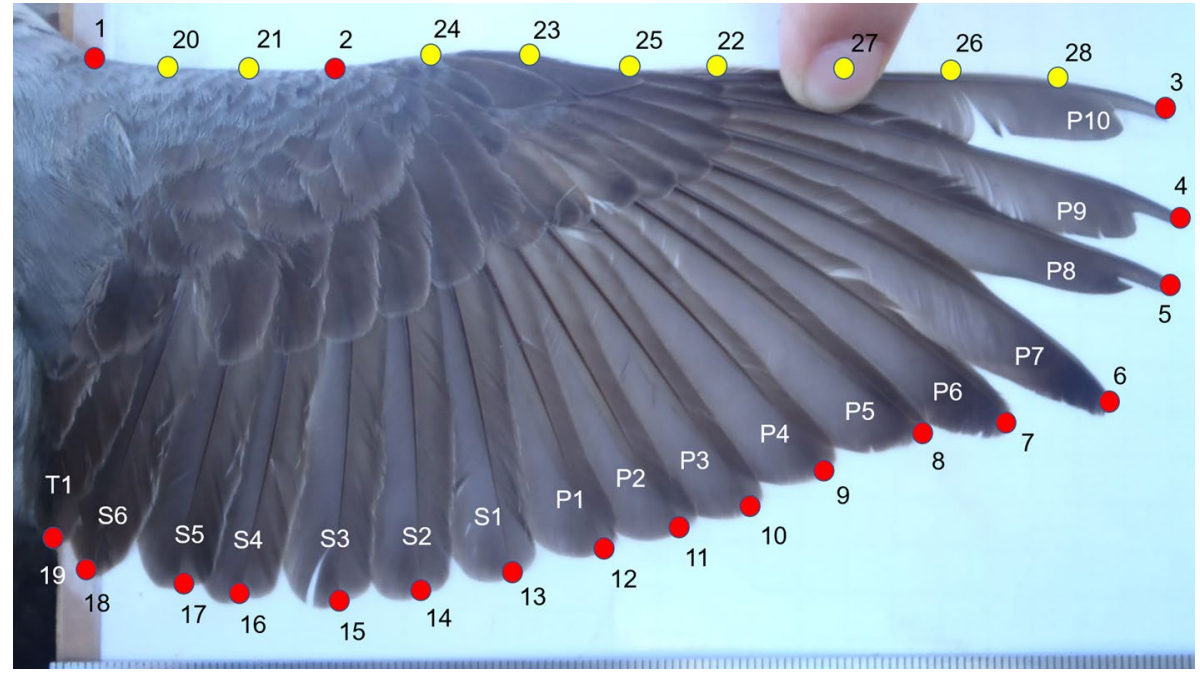

Fig. 2 Image of a Fork-tailed Flycatcher wing showing the location of the 19 landmarks (in red) and nine semi-landmarks (in yellow) for the purpose of landmark-based morphometric analysis. Primary feathers 1 through 10 (P1-10), secondary feathers 1 through 6 (S1-6), and the first tertial feather (T1) are indicated in white alphanumeric text. Ruler ( $1 \mathrm{~mm}$ per mark) shown for reference at the bottom of the image. (Color figure online)

Because migratory birds often store large quantities of fat to fuel their migration (Newton 2010), thus increasing their mass and potentially biasing their wing loading, we estimated subcutaneous fat content of captured flycatchers on an 8-point scale (Ralph et al. 1993). AEJ visited all study sites and compared measurements with researchers at each site to ensure that measurements were standardized among researchers.

We obtained digital images of the dorsal view of the right wing of each flycatcher using a 14 megapixel Olympus Tough (model TG-310 or TG-320) digital camera with a 5.0-18.2 $\mathrm{mm}$ macro lens, positioned $10-30 \mathrm{~cm}$ from the open right wing, held so that the camera lens was parallel to the plane of the wing. The open wing was held on a white sheet of paper on which was printed a grid of $0.64 \times 0.64 \mathrm{~cm}$ or which had a ruler for scale (Fig. 2).

Wing shape was captured from digital images of the right wing obtained from adult flycatchers upon initial capture (i.e., recaptured birds were not included in analyses). We only analyzed images of wings that had no primary or secondary feathers molting, and for which the tips of the primaries and secondaries were not excessively worn or missing. Morphometric variation was then analyzed by calculating aspect ratio, wing pointedness and wing loading, and by employing landmark-based morphometric methods (Mitteroecker and Gunz 2009) to describe overall wing shape (see below).

Analysis of wing length, aspect ratio, loading and pointedness We analyzed the digital images of flycatcher wings to quantify wing length, aspect ratio, wing loading and pointedness. To do so, ICCP measured wing length as the distance between the shoulder and tip of the rachis of the last primary feather in each image (i.e., the distance between points 1 and 3 in Fig. 2) using program ImageJ (rsb.info.nih.gov/ij/) and by quantifying the area of the right wing by digitizing the outer edge of the wing, also in program ImageJ (rsb.info.nih. gov/ij/). We then calculated aspect ratio as the square of two times the length of the right wing divided by two times the area of the right wing (Fiedler 2005). 
We calculated wing loading by dividing body mass by total wing area (i.e., area of the right wing times two; Vanhooydonck et al. 2009). Because estimates of wing loading could be biased due to fattening, we only analyzed wing loading for flycatchers with a trace level (level 1 out of 8 ) of subcutaneous fat or less. We also excluded females that were outliers in terms of high body mass (i.e., greater than 1.5 times the interquartile range above the upper quartile of female masses) because they were likely carrying eggs. Using this filter, we excluded 7 flycatchers with more than trace fat and 2 females that had high mass outliers (no males were found to be outliers). This resulted in 39 females and 65 males used in wing loading analysis. We found no significant difference between the mass of either male $(\mathrm{t}=1.44$, d.f. $=12.4, P=0.17)$ or female $(\mathrm{t}=1.45$, d.f. $=22.1, P=0.16)$ flycatchers with zero versus trace fat levels.

We calculated residual wing length as the residuals of a regression between ln (body mass) and ln (wing length) and residual wing pointedness as the residuals of a regression between wing length and Kipp's Index. We then employed mixed-model nested analysis of variance (ANOVA) to evaluate the effects of sex and migration on wing morphology. In our ANOVAs, morphological variables were response variables, and sex, life history (migratory vs. non-migratory) and breeding population (nested within the life-history term) were explanatory variables. Because we were primarily interested in the effects of sex and migration on wing morphology, we designated the nested population term as a random effect. In addition to providing a more robust statistical test of the primary terms of interest, by treating localities as random effects we were able to generalize our results to other localities not yet sampled. In order to account for potential unique effects of migration in each sex, we initially included a term for the interaction between sex and life history, which was never significant and was removed from models. In order to meet assumptions of normality of model residuals, we ln-transformed aspect ratio and wing loading prior to analysis.

Because we had a priori predictions of how wing length, aspect ratio and pointedness should differ between migratory and non-migratory flycatchers, we conducted one-tailed tests for the life-history term of the models. Finally, we used linear regression to evaluate whether a relationship exists between male tail length and wing length, aspect ratio, wing loading and pointedness.

Landmark-based morphometric analysis Because the wings of birds consist of both an arm-wing and a hand-wing, which serve different functions in terms of generating lift and thrust (Videler et al. 2004; Videler 2006), morphological variation across the entire length of the wing may not be fully described using measurements of linear distances such as wing length and wing pointedness. We therefore further explored variation in flycatcher wing shape by employing landmark-based morphometric analysis, which allows for a much richer description of overall wing shape (e.g., Adams et al. 2013).

This approach involved first registering the 2D Cartesian coordinates of 19 landmarks and nine semi-landmarks on the same images used in the previous analyses, using the tpsDIG (v. 2.28) software (Rohlf 2016a). The following landmarks were used: (1) the shoulder (the middle of the bend between the wing and body; (2) the wrist; and (3) the tip of the rachis of all ten primary feathers, and six secondary feathers, and the first tertial feather (Fig. 2). We used two evenly spaced semi-landmarks between landmarks 1 and 2 and seven evenly spaced semi-landmarks between landmarks 2 and 3 (Fig. 2). All landmarks and semi-landmarks were digitized by ICCP.

The intra-observer error associated with the placement of landmarks and semi-landmarks was evaluated using a subsample of 10 females and 21 males from La Pampa Province, Argentina. To do so, ICCP digitized the same set of landmarks and semi-landmarks 
from the same images in two measurement events separated by more than 1 month. We tested for differences between the two series using a PROTEST analysis (Peres-Neto and Jackson 2001), which tests the congruence between multivariate datasets-in our case, the morphometric shape variables obtained from the two different measurement events)avoiding the risk of type I error associated with multiple comparisons of individual landmarks using repeated-measure ANOVA or intraclass-correlation coefficients (e.g. Gonzalez et al. 2010). We found a Procrustes pseudo-correlation of $0.82(P<0.001)$. The PROTEST analysis was done in the 'vegan' package of program R 3.4.0 (R Development Core Team 2016).

Semi-landmarks are not truly homologous landmarks, although the curves or contours that they describe should be homologous from subject to subject (Bookstein et al. 2002). As a consequence, semi-landmarks must be slid following some criterion of optimization. We used the minimum bending energy criterion, in which individual points were slid so as to minimize the bending energy required for a deformation of the consensus to the selected specimen. Because the wing is an articulated organ and there was the need to find a standard position for image capture, we re-did our analysis considering the tips of the primaries and secondaries as semi-landmarks in order to adjust for arbitrary placements. Results were qualitatively similar using both approaches and we only present the results considering the tips of feathers as true landmarks. We aligned landmarks and semi-landmarks using a generalized Procrustes analysis (i.e., rotating, translating, and scaling coordinates to remove positioning effects and isometric size effects; Rohlf and Slice 1990; Bookstein 1991). The main axes of shape variation were described using Principal Components Analysis (PCA) of the Procrustes shape coordinates (Mitteroecker and Bookstein 2011), which provide low dimensional representations of shape space among specimens. In the case of morphometrics, PCA corresponds to a rigid rotation of the Procrustes shape coordinates that maximizes the variation among individuals (Rohlf 1993). We used the software tpsRelw version 1.65 (Rohlf 2016b) to slide the semi-landmarks.

Differences in overall wing shape between sexes and life histories were tested with nested multivariate analysis of variance (MANOVA) on the first ten principal components of Procrustes coordinates (accounting for $>90 \%$ of shape variation). As before, we used sex, life history and breeding population (nested within life history) as explanatory variables. Random nested factors are not always possible in a MANOVA framework, such that we used only fixed effects. The interaction between sex and life history was not significant and was removed from the model.

In order to determine the nature of morphological divergence associated with model terms of interest, we performed a canonical analysis following Langerhans and Makowicz (2009), and used canonical scores to visualize wing shape variation. Because the sex term was significant and the life-history term was not, we only performed a canonical analysis on the former. Briefly, we conducted a principal components analysis of the sums of squares and the cross-products matrix of the sex term in the MANOVA to derive an eigenvector of divergence ('d') in wing shape between sexes. This divergence vector describes the linear combination of shape variables showing the greatest difference between sexes in Euclidean space, while controlling for other terms in the model (life history and population). We also conducted a mixed-model nested analysis of variance (ANOVA) using ' $d$ ' as the dependent variable. This model was identical to the nested MANOVA except for the fact that ' $d$ ' was the only dependent variable and population nested within life history was designated a random effect.

Shape variation along the divergence vector was visualized using wireframe transformations obtained by performing a multivariate regression of the Procrustes shape 
coordinates on canonical scores. Procrustes superimposition, PCA and multivariate regressions were done in the program MorphoJ 2.0 (Klingenberg 2011). MANOVA and ANOVA were executed in JMP Pro12.1.0 (SAS Institute Inc., Cary, NC).

\section{Results}

We captured and measured 11 females and 9 males at Distrito Federal, Brazil, 14 female and 16 male flycatchers at Estação Ecológica de Itirapina, Brazil, 5 females and 8 males at Reserva Natural El Destino, Argentina, 10 females and 21 males in La Pampa Province, Argentina, 3 females and 3 males in Guyana, and 2 females and 11 males in Colombia, for a total of 45 female and 68 male flycatchers (Table 1). We had relatively few captures in Guyana primarily because densities of breeding individuals there were lower than in Argentina and Brazil (AEJ pers. observation).

Wing length, aspect ratio, loading and pointedness We found no significant effect of sex on $\ln$ (wing loading); however, ANOVA revealed a significant effect of sex on residual wing length, ln (aspect ratio), and residual Kipp's Index (i.e., pointedness; Table 2, Fig. 3), with males exhibiting higher values than females in all cases.

We found no significant effect of life history (i.e., migration vs. permanent residency) on wing length, aspect ratio or wing loading, but there was a non-significant trend for an effect of life history on residual Kipp's Index, with migratory flycatchers having more pointed wings than non-migratory flycatchers (Table 2; Fig. 4).

We found no significant relationship between male tail length and wing length $\left(\mathrm{F}_{1,60}=0.03, P=0.856\right)$, aspect ratio $\left(\mathrm{F}_{1,60}<0.00, P=0.994\right)$, wing loading $\left(\mathrm{F}_{1,57}=1.22\right.$, $P=0.274$ ) or pointedness (Kipp's Index; $\mathrm{F}_{1,36}=1.06, P=0.309$ ). We also tested for a relationship between tail length and a combination of these measures among males (i.e., wing loading + aspect ratio + Kipp's Index), excluding wing length from this full model because aspect ratio and wing length were highly correlated $(\mathrm{r}=0.82)$, and found no significant relationship $\left(\mathrm{F}_{3,31}=0.55, P=0.650\right)$.

Landmark-based morphometrics MANOVA and ANOVA revealed a significant effect of sex but not life history on wing shape (Table 3). Examination of morphological variation along the divergence vector derived from the sex term of the MANOVA revealed that male wings are more swept and taper to a more slender tip than those of females, which have more rounded tips and a leading edge that is less swept (Fig. 5).

Table 1 Mean values $( \pm \mathrm{SD}$; N) for morphological traits of female and male Fork-tailed flycatchers

\begin{tabular}{lcc}
\hline Morphological trait & Females & Males \\
\hline Body mass $(\mathrm{g})$ & $29.0(1.65 ; 38)$ & $30.4(2.19 ; 65)$ \\
Tail length $(\mathrm{cm})$ & $17.6(1.55 ; 34)$ & $23.7(3.01 ; 62)$ \\
Total wing area $\left(\mathrm{cm}^{2}\right)$ & $159.7(14.44 ; 45)$ & $168.4(12.43 ; 68)$ \\
Wing length $(\mathrm{cm})$ & $13.0(1.25 ; 45)$ & $14.0(0.93 ; 68)$ \\
Wing aspect ratio & $4.3(0.64 ; 45)$ & $4.7(0.48 ; 68)$ \\
Wing loading & $0.18(0.017 ; 39)$ & $0.18(0.015 ; 65)$ \\
Wing pointedness $($ i.e., & $3.4(0.28 ; 31)$ & $3.8(0.39 ; 41)$ \\
$\quad$ Kipp's Index/cm) & & \\
\hline
\end{tabular}


Table 2 Mixed-model nested analysis of variance (ANOVA) examining variation in residual wing length, wing aspect ratio, wing loading, and wing pointedness (i.e., residual Kipp's Index) in Fork-tailed Flycatchers

\begin{tabular}{lrlr}
\hline Test for effect on Source & \multicolumn{1}{l}{$F$} & \multicolumn{1}{l}{ d.f. } & \\
\hline Residual wing length & & & \\
$\quad$ Sex & 10.23 & 1,101 & $\mathbf{0 . 0 0 2}$ \\
$\quad$ Life history & 0.02 & $1,13.0$ & 0.440 \\
Ln (aspect ratio) & & & \\
$\quad$ Sex & 11.72 & 1,110 & $<\mathbf{0 . 0 0 1}$ \\
$\quad$ Life history & 0.03 & $1,13.3$ & 0.429 \\
Ln (wing loading) & & & \\
$\quad$ Sex & 0.21 & $1,100.9$ & 0.651 \\
$\quad$ Life history & 0.06 & $1,8.1$ & 0.808 \\
Residual Kipp's Index & & & \\
$\quad$ Sex & 39.69 & $1,65.3$ & $<\mathbf{0 . 0 0 1}$ \\
Life history & 6.48 & $1,2.4$ & 0.052 \\
\hline
\end{tabular}

Life history: non-migratory versus migratory flycatchers. Only fixed effects are shown

$P$ values $<0.05$ are indicated in boldface and $P$ values $<0.10$ are indicated in italics

\section{Discussion}

Overall, we found partial support for our predictions. Migratory Fork-tailed Flycatchers had a non-significant trend of more pointed wings than non-migratory flycatchers; however, wing sweep, wing length and aspect ratio were not related to migration. Males had longer, more pointed, higher aspect ratio, more swept wings with more slender tips than females, regardless of whether they migrate or not, but wing loading did not vary significantly between the sexes. These results suggest that selective pressures associated with sexspecific behaviors play a central role in molding flycatcher wing shape, with migration also molding wing pointedness.

That migratory flycatchers tend to have more pointed wings than non-migratory flycatchers supports the well-documented pattern that migratory birds generally have more pointed wings than non-migratory birds (e.g., Lockwood et al. 1998, Baldwin et al. 2010; Outlaw 2011), as well as a recent study across Tyrannus flycatchers (including migratory and non-migratory Fork-tailed Flycatchers) showing that migrants have more pointed wings than non-migrants (MacPherson 2017). More pointed wings shed weaker vortices and result in lower induced drag (Swaddle and Lockwood, 2003; Tobalsky 2007), resulting in higher flight efficiency, fewer stops during migration and a potentially earlier arrival to the destination (Bowlin 2007; Bowlin and Wikelski 2008). Due to the capacity for some wing traits (e.g., wing pointedness, Egbert and Belthoff 2003) to evolve rapidly, future research should offer valuable insights into the potential for migration to shape migratory bird morphology in different contexts (e.g., MacPherson 2017). For example, compared to migratory birds that breed at north-temperate latitudes and which must travel between continents on an annual basis (e.g., Nearctic-Neotropical migrants), birds that migrate wholly within South America are thought to have fewer barriers to cross (Chesser 1994). Thus, collecting individual-level data on movement (e.g., with satellite transmitters) and morphology on both types of migrants could elucidate whether intra-continental migration exerts a weaker selective pressure on migratory bird morphology than does inter-continental migration. 
Fig. 3 Differences in residual wing length, In (aspect ratio), and residual Kipp's Index between male and female Fork-tailed flycatchers. Values represent the estimated marginal means calculated by mixed-model nested ANOVAs as explained in the text. Bars represent $\pm 1 \mathrm{SE}$
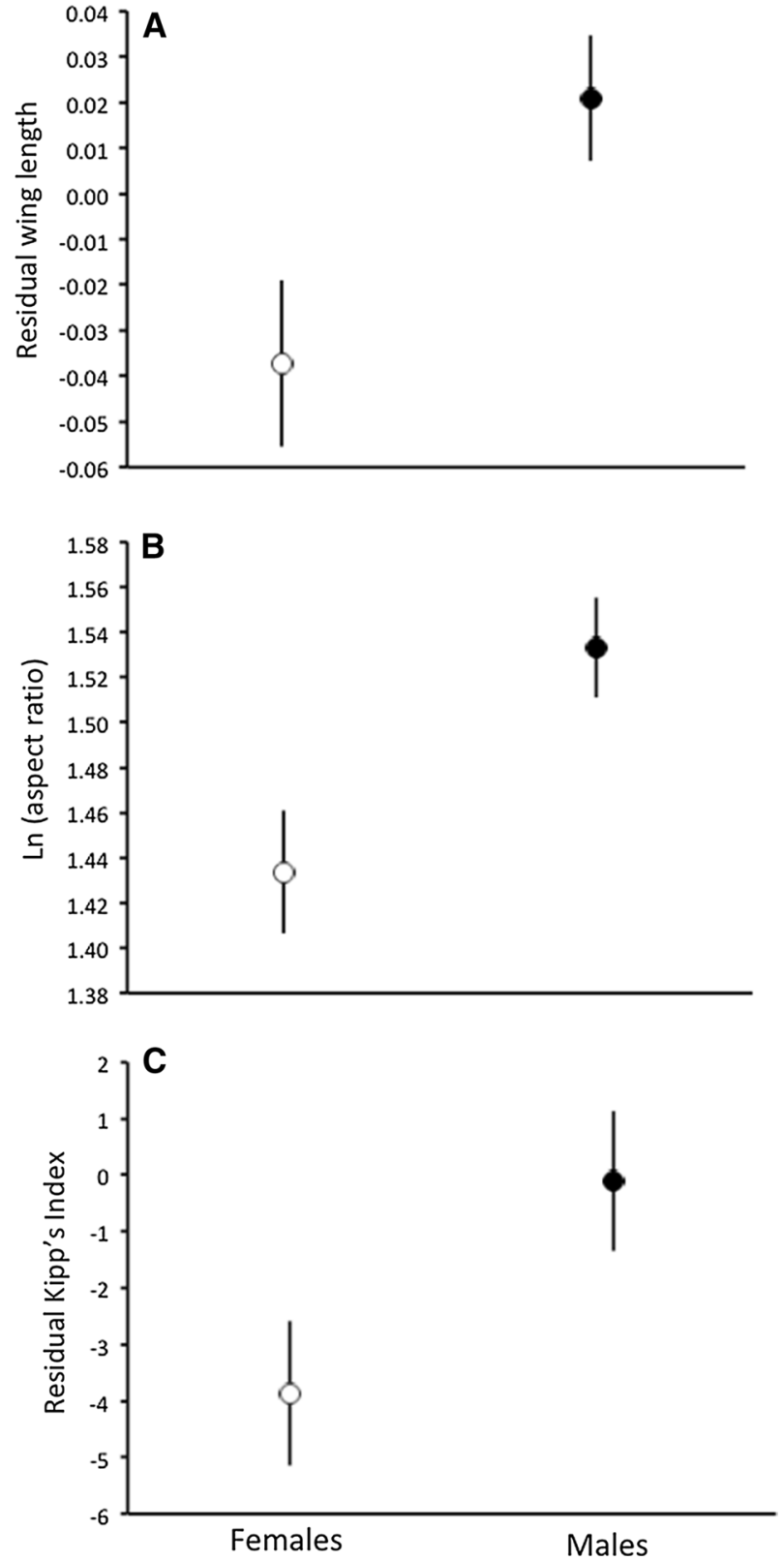

Similar to congeners (e.g., Eastern Kingbirds, Tyrannus tyrannus; Murphy 2007a, b), male Fork-tailed Flycatchers aggressively defend territories throughout the breeding season and compete for mates upon arriving to the breeding area, whereas females focus their energy on nest construction, laying and incubating the eggs (Jahn and Tuero 2013). The higher aspect ratio, longer, more pointed and swept wings of males versus females may be advantageous during such activities as territory defense, since such 


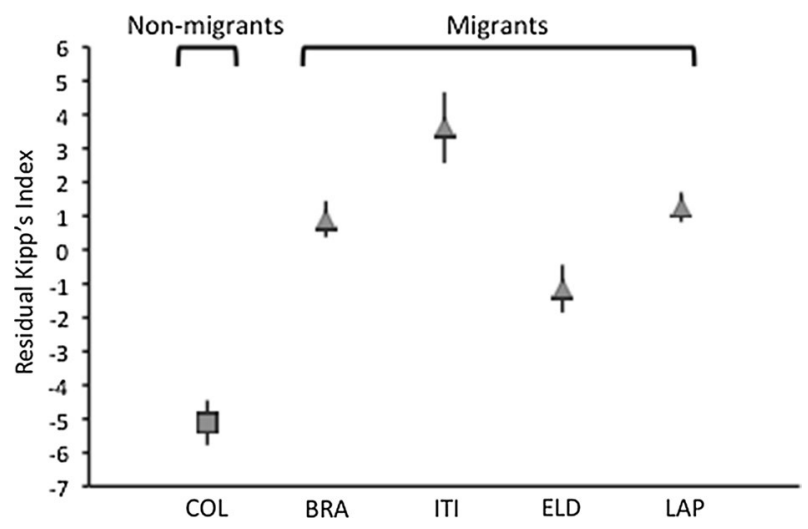

Fig. 4 Differences in residual Kipp's Index between migratory vs. non-migratory flycatchers across study sites. Values represent the estimated marginal means calculated by a mixed-model nested ANOVA as explained in the text. Bars represent \pm 1 SE. Study site abbreviations represent: COL Reserva Natural Y Productiva Tomo Grande, Colombia, BRA Parque da Alvorada, Distrito Federal, Brazil, ITI Estação Ecológica de Itirapina, Brazil, ELD Reserva Natural El Destino, Argentina, LAP Reserva Provincial Parque Luro, Argentina

Table 3 Nested multivariate analysis of variance (MANOVA) examining wing shape in Fork-tailed Flycatchers and mixed-model nested univariate analysis of variance (ANOVA) examining wing shape variation described by the divergence vector (see text)

\begin{tabular}{|c|c|c|c|c|c|c|}
\hline \multirow[t]{2}{*}{ Source } & \multicolumn{3}{|c|}{ MANOVA } & \multicolumn{3}{|c|}{ ANOVA } \\
\hline & $F$ & d.f. & $P$ & $F$ & d.f. & $P$ \\
\hline Sex & 13.23 & 10,97 & $<0.001$ & 48.08 & $1,107.7$ & $<0.001$ \\
\hline Life history & 0.95 & 10,97 & 0.490 & 0.22 & $1,4.2$ & 0.660 \\
\hline Population (life history) & 2.70 & $40,369.7$ & $<0.001$ & & & \\
\hline
\end{tabular}

The population nested term was designated a fixed effect in the MANOVA and a random effect in the ANOVA. Only fixed effects are shown

Significant effects $(P<0.05)$ are indicated in boldface

a wing shape would allow males to fly faster during confrontations with conspecific males. Nevertheless, pointed wings can potentially limit flight maneuverability (Alatalo et al. 1984; Gustafsson 1988), such that the shorter, rounder wings of females are likely beneficial for foraging for agile arthropod prey and escape from predators (Swaddle and Lockwood 1998).

Although wing shape varies substantially between the sexes, we found no significant relationship between tail length and various measures of wing shape (i.e., wing length, aspect ratio, wing loading or pointedness) among Fork-tailed Flycatcher males. In Barn Swallows (Hirundo rustica), which have a deeply forked tail similar to that of Fork-tailed Flycatchers, males with relatively long tails have longer wings, presumably to compensate for the greater drag produced by longer tails (Møller et al. 1995). In turn, male Barn Swallows with longer tails tend to arrive earlier on the breeding grounds than those with shorter tails, acquire mates more rapidly, and enjoy higher reproductive success (Møller 1990, 1994). That wing shape of male Fork-tailed Flycatchers is not related to tail length could potentially be due to the shape of their deeply forked tails, which can provide more 


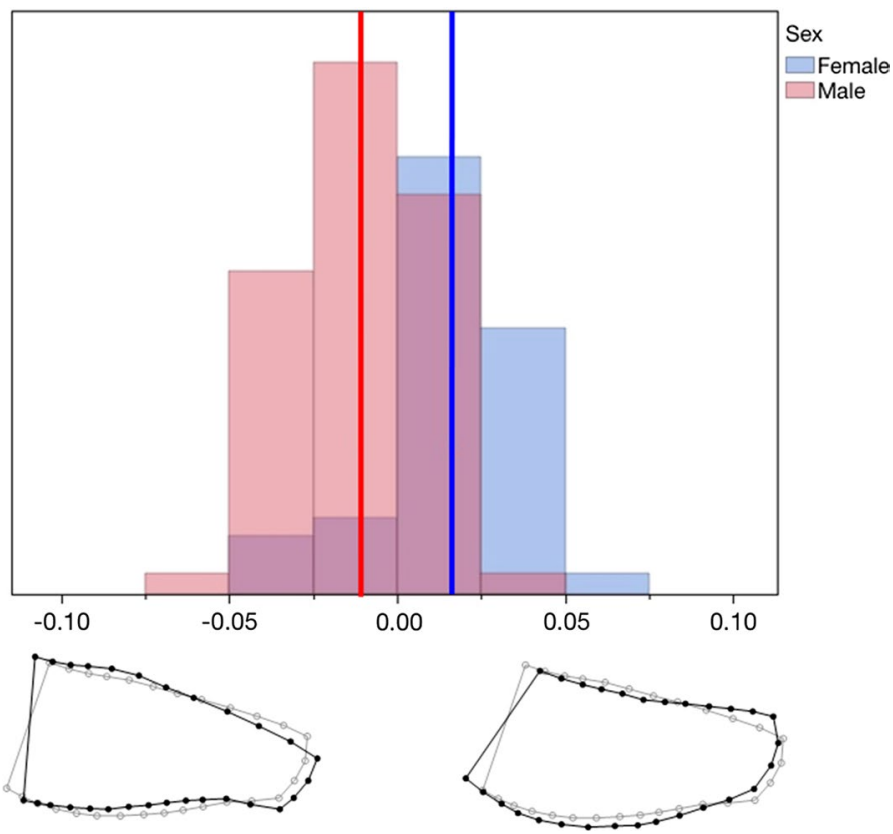

Fig. 5 Wing shape divergence between male and female Fork-tailed flycatchers. Wing shape variation is described by the canonical variate axis derived from MANOVA as explained in the text. Wireframes are estimated changes in wing shape (black) implied by the canonical variate axis for positive and negative deviations from the mean wing shape (consensus; grey). Deformations presented correspond to -0.10 and 0.10 in the axis. Lines represent mean values for each sex

lift and lower drag (Videler 2006). Thus, drag induced by tail length in this species may be minimal, such that flycatcher wing shape is not impacted to a significant degree.

In summary, our results show stronger sex-specific, rather than migration-related differences in wing shape. Given the importance of wing shape for Fork-tailed Flycatchers to migrate, forage on the wing for agile prey, and for males to execute acrobatic displays, wing shape in this species appears to be a product of a complex, interacting suite of tradeoffs, as has been found across the genus Tyrannus (MacPherson 2017).

The multiple evolutionary pressures that shape the overall morphology of an organism are related to a suite of extrinsic variables (e.g., temperate vs. tropical climate), as well as intrinsic mechanisms (e.g., "slower" vs. "faster" avian life history strategies at tropical vs. temperate latitudes, respectively; Wiersma et al. 2007). Given the wide range of life history strategies exhibited by birds across the planet (e.g., birds that breed at north-temperate latitudes generally invest more in annual reproduction than those that breed at tropical or south-temperate latitudes; Jetz et al. 2008), further comparative research across various avian taxa occupying a broad geographic spectrum (e.g., Jahn and Cueto 2012) offers an ideal test of how wing morphology is shaped by life history strategies. Such studies offer a better understanding of the mechanisms shaping the morphology of birds in relation to their need to migrate, reproduce and survive (e.g., Kaboli et al. 2007, Förschler and Bairlein 2011). In turn, understanding the opposing selective pressures shaping the ecology, behavior and morphology of both migratory and sedentary organisms can help us better understand current and future risks to their survival on a rapidly changing planet. 
Acknowledgements We thank three anonymous reviewers and the Associate Editor, who provided many useful comments that greatly improved the manuscript. We are grateful to numerous assistants and collaborators, in particular J. Cereghetti, V.R. Cueto, V. Gómez-Bahamón, M.A. Pizo, M.Â. Marini, J.H. Sarasola and D.T. Tuero, without whom this project would not have been possible. We are grateful to the Fundación Elsa Shaw de Pearson for logistical support. This research was funded by Optics for the Tropics and the Fundação de Amparo á Pesquisa do Estado de São Paulo-Brazil (2012/17225-2, 2013/19116-9). Research was conducted in Argentina with approval from Subsecretaria de Ecologia, Gobierno de La Pampa, and Departamento de Flora y Fauna, Ministerio de Asuntos Agrarios, Provincia de Buenos Aires (Disposición 256/11), in Brazil by the Ministério do Meio Ambiente (40221-1) and COTEC-São Paulo (260108008.399/2013), CEMAVE (3819/1). This study was approved by the Animal Use Ethics Commission at UNESP-Rio Claro under permit 3/2014. The authors declare no conflicts of interest.

\section{References}

Adams DC, Rohlf FJ, Slice DE (2013) A field comes of age: geometric morphometrics in the 21st century. Hystrix 24:7-14

Alatalo RV, Gustafsson L, Lundberg A (1984) Why do young passerine birds have shorter wings than older birds? Ibis 126:410-415

Areta JI, Miller EH (2014) Display flight and mechanical sounds of the Andean negrito (Lessonia oreas), with comments on the basic structure of flight displays in Fluvicoline flycatchers. Ornitol Neotrop 25:95-105

Arizaga J, Campos F, Alonso D (2006) Variations in wing morphology among subspecies might reflect different migration distances in Bluethroat. Ornis Fennica 83:162-169

Baldwin MW, Winkler H, Organ CL et al (2010) Wing pointedness associated with migratory distance in common-garden and comparative studies of stonechats (Saxicola torquata). J Evol Biol 23:1050-1063

Balmford A, Jones IL, Thomas AL (1994) How to compensate for costly sexually selected tails: the origin of sexually dimorphic wings in long-tailed birds. Evolution 48:1062-1070

Bookstein FL (1991) Morphometric tools for landmark data. Cambridge University Press, Cambridge

Bookstein FL, Streissguth AP, Sampson PD et al (2002) Corpus callosum shape and neuropsychological deficits in adult males with heavy fetal alcohol exposure. Neuroimage 15:233-251

Bowlin MS (2007) Sex, wingtip shape, and wing-loading predict arrival date at a stopover site in the Swainson's Thrush (Catharus ustulatus). Auk 124:1388-1396

Bowlin MS, Wikelski M (2008) Pointed wings, low wing loading and calm air reduce migratory flight costs in songbirds. PLoS ONE 3:e2154

Buler JJ, Lyon RJ, Smolinsky JA et al (2017) Body mass and wing shape explain variability in broad-scale bird species distributions of migratory passerines along an ecological barrier during stopover. Oecologia 185:205-212

Byers BE (2011) Birdsong, migration and sexual selection: a skeptical view. Anim Behav 82:e1-e3

Chesser RT (1994) Migration in South America: an overview of the Austral system. Bird Conserv Int 4:91-107

Collins SA, de Kort SR, Pérez-Tris J et al (2009) Migration strategy and divergent sexual selection on bird song. Proc R Soc Lond B Biol Sci 276:585-590

Corman AM, Bairlein F, Schmaljohann H (2014) The nature of the migration route shapes physiological and aerodynamic properties in a migratory songbird. Behav Ecol Sociobiol 68:391-402

de la Hera I, Pulido F, Visser ME (2014) Longitudinal data reveal ontogenetic changes in the wing morphology of a long-distance migratory bird. Ibis 156:209-214

Egbert JR, Belthoff JR (2003) Wing shape in House Finches differs relative to migratory habit in eastern and western North America. Condor 105:825-829

Fernández G, Lank DB (2007) Variation in the wing morphology of Western Sandpipers (Calidris mauri) in relation to sex, age class, and annual cycle. Auk 124:1037-1046

Fiedler W (2005) Ecomorphology of the external flight apparatus of blackcaps (Sylvia atricapilla) with different migration behavior. Ann N Y Acad Sci 1046:253-263

Fitzpatrick JW (2004) Family Tyrannidae (tyrant flycatchers). In: del Hoyo J, Elliott A, Sargatal J (eds) Handbook of the birds of the world, vol 9. Cotingas to pipits and wagtails. Lynx Edicions, Barcelona, pp 170-462

Förschler MI, Bairlein F (2011) Morphological shifts of the external flight apparatus across the range of a passerine (Northern Wheatear) with diverging migratory behaviour. PLoS ONE 6(4):e18732. https:// doi.org/10.1371/journal.pone.0018732 
Gonzalez PN, Perez SI, Bernal V (2010) Ontogeny of robusticity of craniofacial traits in modern humans: a study of South American populations. Am J Phys Anthropol 142:367-379

Gustafsson L (1988) Foraging behavior of individual coal tits, Parus ater, in relation to their age, sex and morphology. Anim Behav 36:696-704

Hahn S, Korner-Nievergelt F, Emmenegger T et al (2016) Longer wings for faster springs—wing length relates to spring phenology in a long-distance migrant across its range. Ecol Evol 6:68-77

Hedenström A, Møller AP (1992) Morphological adaptations to song flight in passerine birds: a comparative study. Proc R Soc Lond B Biol Sci 247:183-187

Hedenström A, Pettersson J (1986) Differences in fat deposits and wing pointedness between male and female Willow Warblers caught on spring migration at Ottenby, SE Sweden. Orn Scand 17:182-185

Hilty SL, Brown B (1986) A guide to the birds of Colombia. Princeton University Press, Princeton

Jahn AE, Cueto VR (2012) The potential for comparative research across New World bird migration systems. J Ornithol 153:199-205

Jahn AE, Tuero DT (2013) Fork-tailed Flycatcher (Tyrannus savana). In: Schulenberg TS (ed) Neotropical birds. Online Cornell Lab of Ornithology, Ithaca

Jahn AE, Levey DJ, Cueto VR et al (2013) Long-distance bird migration within South America revealed by light-level geolocators. Auk 130:223-229

Jahn AE, Seavy NE, Bejarano V et al (2016) Intra-tropical migration and wintering areas of Fork-tailed Flycatchers (Tyrannus savana) breeding in São Paulo, Brazil. Braz J Ornithol 24:116-121

Jahn AE, Bejarano V, Benavides Guzmán M et al (2017) Molt while breeding? Lessons from New World Tyrannus flycatchers. J Ornithol 158:1061-1072

Jetz W, Sekercioglu CH, Böhning-Gaese K (2008) The worldwide variation in avian clutch size across species and space. PLoS Biol 6:e303

Kaboli M, Aliabadian M, Guillaumet A et al (2007) Ecomorphology of the wheatears (genus Oenanthe). Ibis 149:792-805

Kaluthota C, Brinkman BE, dos Santos EB et al (2016) Transcontinental latitudinal variation in song performance and complexity in house wrens (Troglodytes aedon). Proc R Soc B 283:20152765

Klingenberg CP (2011) MorphoJ: an integrated software package for geometric morphometrics. Mol Ecol Res 11:353-357

Langerhans RB, Makowicz AM (2009) Shared and unique features of morphological differentiation between predator regimes in Gambusia caymanensis. J Evol Biol 22:2231-2242

Lockwood R, Swaddle JP, Rayner JM (1998) Avian wingtip shape reconsidered: wingtip shape indices and morphological adaptations to migration. J Avian Biol 29:273-292

MacPherson MP (2017) Migration patterns in birds of the new world: seasonal, morphometric and physiological considerations. Dissertation, Tulane University

Marchetti K, Price T, Richman A (1995) Correlates of wing morphology with foraging behavior and migration distance in the genus Phylloscopus. J Avian Biol 26:177-181

Marini MÂ, Lobo Y, Lopes LE et al (2009) Biologia reprodutiva de Tyrannus savana (Aves, Tyrannidae) em cerrado do Brasil Central. Biota Neotrop 9:55-63

Milá B, Wayne RK, Smith TB (2008) Ecomorphology of migratory and sedentary populations of the Yellow-rumped Warbler (Dendroica coronata). Condor 110:335-344

Minias P, Meissner W, Włodarczyk R et al (2015) Wing shape and migration in shorebirds: a comparative study. Ibis 157:528-535

Mitteroecker P, Bookstein F (2011) Linear discrimination, ordination, and the visualization of selection gradients in modern morphometrics. Evol Biol 38:100-114

Mitteroecker P, Gunz P (2009) Advances in geometric morphometrics. Evol Biol 36:235-247

Mobley JM (2004) Fork-tailed Flycatcher Tyrannus savana. In: del Hoyo J, Elliot A, Christie D (eds) Handbook of the birds of the world. Contingas to pipits and wagtails, vol 9. Lynx Edicions, Barcelona, p 425

Møller AP (1990) Male tail length and female mate choice in the monogamous swallow Hirundo rustica. Anim Behav 39:458-465

Møller AP (1994) Phenotype-dependent arrival time and its consequences in a migratory bird. Behav Ecol Sociobiol 35:115-122

Møller AP, De Lope F, Saino N (1995) Sexual selection in the barn swallow Hirundo rustica. VI. Aerodynamic adaptations. J Evol Biol 8:671-687

Mönkkönen M (1995) Do migrant birds have more pointed wings?: A comparative study. Evol Ecol 9:520-528

Morbey YE, Ydenberg RC (2001) Protandrous arrival timing to breeding areas: a review. Ecol Lett 4:663-673 
Murphy MT (2007a) A cautionary tale: cryptic sexual size dimorphism in a socially monogamous passerine. Auk 124:515-525

Murphy MT (2007b) Lifetime reproductive success of female Eastern Kingbirds (Tyrannus tyrannus): influence of lifespan, nest predation, and body size. Auk 124:1010-1022

Newton I (2010) The migration ecology of birds. Academic Press, London

Outlaw DC (2011) Morphological evolution of some migratory Ficedula flycatchers. Contrib Zool $80: 279-284$

Pennycuick CJ (1972) Animal flight. Arnold Press, London

Pennycuick CJ (2008) Modelling the flying bird, vol 5. Elsevier, Toronto

Peres-Neto P, Jackson D (2001) How well do multivariate data sets match? The advantages of a Procrustean superimposition approach over the Mantel test. Oecologia 129:169-178

Pérez-Tris J, Tellería JL (2001) Age related variation in wing shape of migratory and sedentary Blackcaps Sylvia atricapilla. J Avian Biol 32:207-213

Pyle P (1997) Identification guide to North American birds, Part I. Slate Creek Press Bolinas, California

R Development Core Team (2016) R: a Language and environment for statistical computing. R Foundation for Statistical Computing, Vienna

Ralph CJ, Guepel GR, Pyle P et al (1993) Handbook of field methods for monitoring landbirds. U.S. Forest Service General Technical Report PSW-GTR-144, California

Rayner JMV (1988) Form and function in avian flight. Curr Ornithol 5:1-66

Regosin JV, Pruett-Jones S (1995) Aspects of breeding biology and social organization in the Scissor-tailed Flycatcher. Condor 97:154-164

Rohlf FJ (1993) Relative warp analysis and an example of its application to mosquito wings. Contrib Morphometr 8:131-159

Rohlf FJ (2016a). TpsDig 2.28. Available at http://life.bio.sunysb.edu/morph

Rohlf FJ (2016b). TpsRelw 1.65. Available at http://life.bio.sunysb.edu/morph

Rohlf FJ, Slice DE (1990) Extensions of the procrustes method for the optimal superimposition of landmarks. Syst Zool 39:40-59

Smith WJ (1966) Communications and relationships in the genus Tyrannus. Publ Nuttall Ornithol Club 6:1-250

Swaddle JP, Lockwood R (1998) Morphological adaptations to predation risk in passerines. J Avian Biol 29:172-176

Swaddle JP, Lockwood R (2003) Wingtip shape and flight performance in the European starling Sturnus vulgaris. Ibis 145:457-464

Thomas AL, Balmford A (1995) How natural selection shapes birds' tails. Am Nat 146:848-868

Tobalsky BW (2007) Biomechanics of bird flight. J Exp Biol 210:3135-3146

Vágási CI, Pap PL, Vincze O et al (2016) Morphological adaptations to migration in birds. Evol Biol 43:48-59

van Oorschot BK, Mistick EA, Tobalske BW (2016) Aerodynamic consequences of wing morphing during emulated take-off and gliding in birds. J Exp Biol 219:3146-3154

Vanhooydonck B, Herrel A, Gabela A et al (2009) Wing shape variation in the medium ground finch (Geospiza fortis): an ecomorphological approach. Biol J Linn Soc 98:129-138

Videler JJ (2006) Avian flight. Oxford University Press, Oxford

Videler JJ, Stamhuis EJ, Povel GDE (2004) Leading-edge vortex lifts swift. Science 306:1960-1962

Voelker G (2001) Morphological correlates of migratory distance and flight display in the avian genus Anthus. Biol J Linn Soc 73:425-435

Wiersma P, Muñoz-Garcia A, Walker A, Williams JB (2007) Tropical birds have a slow pace of life. Proc Natl Acad Sci 104:9340-9345

Winkler H, Leisler B (1992) On the ecomorphology of migrants. Ibis 134:21-28

Yong W, Moore FR (1994) Flight morphology, energetic condition, and the stopover biology of migrating thrushes. Auk 111:683-692 